Cahiers $d u$ MONDE RUSSE

\section{Cahiers du monde russe}

Russie - Empire russe - Union soviétique et États indépendants

$46 / 4 \mid 2005$

L'invention d'une politique humanitaire

\title{
Sandra Teroni, Wolfgang Klein, éds., Pour la défense de la culture
}

\section{Michel Aucouturier}

\section{OpenEdition \\ Journals}

Édition électronique

URL : https://journals.openedition.org/monderusse/6620

DOI : 10.4000/monderusse. 6620

ISSN : $1777-5388$

Éditeur

Éditions de l'EHESS

\section{Édition imprimée}

Date de publication : 1 décembre 2005

Pagination : 919-921

ISBN : 2-7132-2057-2

ISSN : $1252-6576$

Référence électronique

Michel Aucouturier, «Sandra Teroni, Wolfgang Klein, éds., Pour la défense de la culture », Cahiers du monde russe [En ligne], 46/4 | 2005, mis en ligne le 29 juin 2009, consulté le 02 septembre 2022. URL : http://journals.openedition.org/monderusse/6620 ; DOI : https://doi.org/10.4000/monderusse.6620

Ce document a été généré automatiquement le 2 septembre 2022

Tous droits réservés 


\title{
Sandra Teroni, Wolfgang Klein, éds., Pour la défense de la culture
}

\author{
Michel Aucouturier
}

\section{RÉFÉRENCE}

Pour la défense de la culture. Les textes du Congrès international des écrivains, Paris, juin 1935, réunis et présentés par Sandra TERONI et Wolfgang KLEIN. Dijon : Éditions universitaires de Dijon, 2005, 665 p. (Collection Sources)

1 Le Congrès international des écrivains pour la défense de la culture, qui, du 21 au 25 juin 1935, a attiré à Paris, dans la salle de la Mutualité, un public de plusieurs milliers de personnes venues entendre quelques grandes célébrités de la littérature mondiale (Gide, Forster, Huxley, Valle-Inclán, Martin Andersen-Nexö, Malraux, Brecht, Heinrich Mann, Aragon, Tristan Tzara, Aleksej Tolstoj, Erenburg, Pasternak, Babel', Nezval) marque l'apogée éphémère d'une grande illusion: celle d'une alliance durable, face au danger nazi, entre les intellectuels de gauche des pays occidentaux, attachés aux idéaux de liberté et de progrès, et le monde communiste représenté par l'URSS, alliance impliquant plus largement une prise en charge par le communisme de l'idéal humaniste de la culture universelle.

2 Cet ouvrage, comme l'indique dans sa préface l'historien Serge Wolikow, directeur de la Maison des sciences de l'homme de Dijon, qui en a pris l'initiative (et a réuni pour le réaliser une importante équipe de traducteurs et de rédacteurs, dont il faut saluer le travail), «met pour la première fois à la disposition du public francophone l'ensemble des documents de ce congrès ", réunis et publiés d'abord en allemand, dès 1982, par Wolfgang Klein, actuellement professeur à l'université d'Osnabrück. C'est l'immense travail de recherche accompli par ce dernier dans les archives du Komintern, à Moscou, et du parti communiste allemand à Berlin, mais également dans une vingtaine de fonds d'archives de Paris, Moscou, Berlin, Francfort, Copenhague, Prague, Ludwigshafen, Zurich, qui lui a permis en effet de reconstituer et de réunir ces textes, qui n'avaient été 
publiés jusque-là que très partiellement dans un volume édité à Moscou en 1936 par le critique et historien de la littérature Ivan Luppol, membre de la délégation soviétique au congrès.

3 Ces recherches ont permis à Wolfgang Klein de présenter pour la première fois, dans une importante et substantielle préface, l'histoire complexe de la préparation de ce congrès, qui en éclaire les enjeux et le sens. La conclusion paradoxale à laquelle aboutit cette passionnante étude, appuyée en particulier sur la correspondance inédite des protagonistes, est que si les communistes, intellectuels et écrivains, des pays occidentaux, essentiellement de France et d'Allemagne (Barbusse, Aragon, Johannes Becher) avec l'appui de certains « compagnons de route » éminents, comme Romain Rolland, André Gide ou Heinrich Mann, ont effectivement été à l'origine du congrès, le parti communiste soviétique (c'est-à-dire Stalin) et sa direction internationale (le Komintern) se sont montrés singulièrement en retrait. Il est certain que, dans l'esprit de l'un de ses premiers initiateurs, Henri Barbusse, qui était allé chercher à Moscou la bénédiction de Stalin lui-même (et croyait l'avoir obtenue), ce congrès devait traduire à l'échelle internationale ce qu'avait été le congrès inaugural de l'Union des écrivains soviétiques de Moscou en 1934, et signifier la liquidation de l'Association internationale des écrivains révolutionnaires (AIER, en russe MORP), extension de la RAPP, autoritairement dissoute en 1932 au profit d'une association plus large, étendant le contrôle du parti aux "compagnons de route» non communistes, association dont Barbusse lui-même aurait pris la direction. L'indécision de Moscou (due peut-être aux débats entourant le VII ${ }^{\mathrm{e}}$ congrès du Komintern, qui, en août 1935, allait marquer un tournant dans la stratégie internationale du communisme) devait faire échapper l'initiative à Barbusse et la laisser aux mains de dirigeants de l'AIER, tels que Johannes Becher ou Aragon, convertis eux aussi, il est vrai, à la nouvelle politique de large rassemblement. L'une des raisons de la prudence du pouvoir soviétique est certainement la conscience de l'impossibilité de transposer à l'échelle internationale la prise de contrôle de la littérature par le parti réalisée en URSS à l'initiative de Stalin lui-même.

Sandra Teroni, elle, retrace dans une préface également très substantielle le développement du mouvement antifasciste qui va amener au congrès de nombreux intellectuels appartenant à la gauche libérale ou socialisante, comme Julien Benda ou Jean Guéhenno, et en analyse les débats. Les questions proposées aux congressistes ont été formulées de façon très large et, si certains orateurs utilisent la tribune pour mettre en accusation le régime politique de leur pays (et en particulier le nazisme), la plupart des interventions traitent de questions très générales, telles que la liberté de création ou "l'artiste et la société ». Cependant le problème de l'engagement de l'écrivain laisse apparaitre plus ou moins nettement des clivages politiques. Les écrivains communistes (confortés par la « salutation fraternelle » envoyée par Romain Rolland « en chemin vers le pays où l'on crée le monde nouveau » : il doit rencontrer à Moscou Gor'kij et Stalin) identifient plus ou moins explicitement la défense de la culture à la cause de l'URSS. Leurs positions sont critiquées à droite par Julien Benda, qui défend l'indépendance de l'écrivain, à gauche par Brecht, qui oppose implicitement à la nouvelle ligne humaniste défendue par Moscou l'« analyse de classe » prônée par le marxisme et par Breton qui dénonce comme une concession à l'ordre bourgeois le pacte d'assistance mutuelle qui vient d'être signé entre l'URSS et la France.

5 Ces critiques tournent parfois à la mise en cause directe du "pays du socialisme»: l'historien antifasciste italien Gaetano Salvemini et la trotskiste Madeleine Paz n'hésitent pas à prendre le contre-pied des organisateurs, l'un en refusant d'assimiler la 
démocratie bourgeoise au fascisme et en dénonçant les atteintes à la liberté en URSS, l'autre en soulevant le cas de l'écrivain d'origine russe Victor Serge, revenu en Russie au lendemain de la révolution, et qui avait été envoyé en Sibérie en résidence surveillée pour son adhésion à l'opposition trotskiste. Son intervention entraîne une violente réplique des membres de la délégation soviétique, l'« occidental» Il'ja Erenburg compris, qui défendent le droit de l'URSS de châtier ses ennemis, et vont même jusqu'à accuser Victor Serge de complicité dans l'assassinat de Kirov, qui a pourtant eu lieu plusieurs mois après son éloignement. Cet incident révèle la façon dont la délégation de l'Union des écrivains soviétiques, choisie du reste par le Comité central, conçoit son rôle au congrès : ses membres se comportent en représentants officiels et en propagandistes de l'URSS, dont ils donnent dans leurs discours une description idyllique. Seuls Pasternak et Babel', adjoints au dernier moment et contre leur gré (du moins pour le premier) à la délégation soviétique, à la demande instante des organisateurs, s'exprimeront en leur propre nom, mais, ovationnés par la salle, ils ne feront que de la figuration.

6 Apparemment noyée sous l'esprit de coopération internationale affiché par le congrès, la mise en cause de l'URSS, qui s'exprime encore timidement à travers certaines interventions, en traduit en réalité l'échec. L'Association internationale des écrivains pour la défense de la culture, dont il a jeté les fondations, et qui devait prendre la relève de l'Association internationale des écrivains prolétariens, dissoute en 1935 (comme l'Union des écrivains soviétiques avait pris en URSS celle de la RAPP), a fait long feu : les péripéties complexes de sa brève histoire sont étudiées dans un "Épilogue " de Wolfgang Klein, avec autant de minutie et de précision documentaire que sa préparation.Objet d'un travail considérable de rédaction et de traduction, illustré de dessins, de photos et de reproductions de documents manuscrits, pourvu d'un important appareil de notes, de substantielles notices biographiques sur tous les orateurs du congrès, d'une abondante bibliographie et enfin d'un index de plusieurs pages, nous avons là un ouvrage de référence précieux et sûr, indispensable à tous ceux qui s'intéressent à l'histoire intellectuelle de l'Europe à la veille de la Seconde Guerre mondiale, et à celle du communisme. 